As recently as 1999 , the situation in New South Wales has again changed. At a hearing concerning a 19-year-old severely ill patient with anorexia nervosa, Mrs Brennan, senior member of the Mental Health Tribunal, decided that she was a mentally ill person, and hence did fall under the Act even though anorexia nervosa as such was not considered a mental illness (mine not to comment on the niceties of the use of words in law, merely to report). This brings our State in line with legislation in the UK, and other states of Australia.

Griffiths, R. A., Beumont, P. J.V., Russell, J., et al (1997) The use of guardianship legislation for anorexia nervosa: a report of 15 cases. Australian and New Zealand Journal of Psychiatry, 31, 524-531.

Ramsay, R., Ward, A., Treasure, J., et al (1999) Compulsory treatment in anorexia nervosa. Short-term benefits and long-term mortality. British Journal of Psychiatry, 175, 147-153.

Vandereycken, W. \& Beumont, P. J. V. (eds) (1999)

Treating Eating Disorders: Ethical, Legal and Personal Issues. London: Athlone Press.

P. J.V. Beumont Department of Psychological Medicine, Faculty of Medicine, The University of Sydney, NSW 2006, Australia

\section{Resource allocation for mental health care}

We read with interest the editorial by Gyles Glover on allocations to health authorities for mental health care (Glover, 1999). It is important that the sums of money allocated to health authorities for mental health care be widely known. This will allow all interested parties to have ready access to information upon which to base any claims about the adequacy or otherwise of funds made available to health care providers.

We are aware there is wide variation in the amounts actually spent by health authorities, as opposed to the amounts allocated. For example, in the year 1997/98 Worcester Health Authority spent $£ 24$ per head of population on mental illness (excluding mental handicap), Solihull Health Authority spent $£ 32$ per head of population, and Lambeth and Southwark spent $£ 138$ (Chartered Institute of Public Finance and Accountancy, 1998). These amounts represent 4, 5.5 and 17.4 per cent, respectively, of the overall expenditure on health care per head of population. We do not have any information on the actual amounts allocated to health authorities in this period, but are concerned at the observed variation.
We do not believe that this variation can be easily explained.

There is cause for further concern. The York formula, which is used in determining the level of resource allocation, for example, ranks Birmingham 8th in order of need but 20th in order of spend per head of population. But more worryingly, Birmingham is ranked 38th in order of spend: needs index ratio (further details available from Dr Oyebode upon request). This suggests that whatever the actual amount of money allocated, using a formula devised to take account of factors predictive of high psychiatric morbidity, health authorities may not be spending the indicative amounts allocated to them

We believe that it is important that mental health services be adequately funded. The transparency of the arrangements for funding will become even more important as we move into an environment controlled by primary care groups or trusts. The risk is that substantial sums will be allocated but not spent on mental health services. It is clear that this is already the case but the situation could very well worsen if there is no control in the system.

Chartered Institute of Public Finance and Accountancy (1998) 1997/98 Health Authority accounts summarisation schedule HAAOI. In The Health Service Database. London: IPF

Glover, G. (1999) How much English health authorities are allocated for mental health care. British Journal of Psychiatry, 175, 402-406.

N. Brown Solihull Healthcare NHS Trust, Lyndon Clinic, Hobs Meadow, Solihull B92 8PW

F. Oyebode South Birmingham Mental Health NHS Trust, Queen Elizabeth Psychiatric Hospital, Mindelsohn Way, Edgbaston, Birmingham BI5 2QZ

\section{Fluoxetine-induced anaesthesia of vagina and nipples}

Antidepressant drugs cause a variety of sexual side-effects. However, antidepressantinduced changes in sexual sensations are rare. We report a case of fluoxetineinduced loss of sensation of vagina and nipples.

A 48-year-old married woman with recurrent depression had good antidepressant response to fluoxetine $20 \mathrm{mg}$. However, her compliance with the medication was poor resulting in recurrences. While euthymic and on no antidepressants, her sexual function was normal. When depressed she has moderate decrease in libido. With fluoxetine $20 \mathrm{mg}$ her depression remitted and her libido returned to normal. However, she developed a complete loss of sexual sensation of her nipples and vagina. Touch and pain sensations were also impaired, but only to a lesser extent. This lead to decreased satisfaction with sexual life and consequently poor compliance with the medication. Even when she became briefly hypomanic on fluoxetine, the lack of sensation persisted. We substituted her fluoxetine with trazodone $400 \mathrm{mg}$. She remained euthymic. By the fifth week her vaginal and nipple sensations returned to normal. The frequency of sexual intercourse and satisfaction improved to premorbid levels.

This is the first report of fluoxetineinduced loss of sensation of vagina and nipples. Fluoxetine-induced anaesthesia of penis (Neill, 1991; Measom, 1992) and vagina (King \& Horowitz, 1993), which did not improve with dosage reduction or addition of cyproheptadine, but did with discontinuation of fluoxetine, have been reported. Ellison \& DeLuca (1998) reported a case of genital anaesthesia caused by fluoxetine that did not improve with addition of cyproheptadine or yohimbine but responded to Ginkgo biloba. Ginkgo biloba is a Chinese herbal remedy for a variety of disorders and has diverse neurochemical effects. The mechanism of antidepressant-induced sexual anaesthesia remains elusive. The fact that the anaesthesia persisted even during the fluoxetine-induced hypomanic state confirms that this was not part of the depressive syndrome.

Sexual side-effects of antidepressant drugs cause distress, strain relationships, impair quality of life and reduce compliance with treatment. Enquiring routinely about side-effects, especially sexual sideeffects of antidepressants, would help to improve compliance with treatment.

Ellison, J. M. \& DeLuca, P. (1998) Fluoxetine-induced genital anaesthesia relieved by Ginkgo biloba extract. Journal of Clinical Psychiatry, 59, 199-200.

King, V. L. \& Horowitz, I. R. (1993) Vaginal anesthesia associated with fluoxetine use. American Journal of Psychiatry, I50, 984-985.

Measom, M. O. (1992) Penile anaesthesia and fluoxetine. American Journal of Psychiatry, 149, 709.

Neill, J. R. (1991) Penile anaesthesia associated with fluoxetine. American Journal of Psychiatry, 148, 1603.

A. Michael, C. Mayer Department of Psychiatry, West Suffolk Hospital, Bury St Edmunds IP33 2QZ 